\title{
THE PARADOXES OF TOLERANCE: A DECONSTRUCTIVE VIEW*
}

Keywords: tolerance, paradoxes, Derrida, Forst, Habermas

Słowa kluczowe: tolerancja, paradoksy, Derrida, Forst, Habermas

\section{Introduction}

Preston King (1998, pp. xii-xiii) makes a distinction between toleration, broadly speaking, and tolerance as a specific subset of it. According to this understanding, toleration can encompass different sorts of attitudes and actions, including, for example, favouritism. The latter entails not only toleration of different worldviews, or ways of life, but also a certain promotional attitude. In contrast, tolerance is an attitude that entails acceptance of a worldview that is otherwise explicitly rejected, or may even be disdained.

* Giorgi Tskhadaia - PhD, Associate Professor of Political Science, Caucasus School of Governance, Caucasus University, Tbilisi, Georgia. Interests: Agonistic and deliberative models of democracy, the theories of fairness, cosmopolitanism.

Address for correspondence: Caucasus University, Caucasus School of Governance, Tbilisi, Georgia. E-mail: gtskhadaia@cu.edu.ge.

** The present article is based on the author's $\mathrm{PhD}$ dissertation defended at Pompeu Fabra University in 2020. 
Tolerance leads to a starkly ambivalent stance and gives rise to paradoxes or aporias. Its first major paradox stems from the fact that, as T.M. Scanlon puts it, tolerance requires an "attitude that is intermediate between wholehearted acceptance and unrestrained opposition" (Heyd, 1996 , p. 226). In other words, a tolerant person is supposed to tolerate something that she strongly opposes but somehow finds permissible to accept. What can be tolerated is sometimes an ethical doctrine but, in other cases, it could be a way of life or even an aesthetic preference. As the most pressing examples of tolerance involve comprehensive doctrines -including religions, I will be mainly concerned with such cases. The terms "ethical doctrine" and "comprehensive doctrine" will be used interchangeably in this article. They will be juxtaposed against neo-Kantian moral reasoning. I use the term "normativity" to denote both ethical and moral (neo-Kantian) judgments. In all instances, the requirement is that a tolerant person has to accept something that has been already rejected. For example, one may find a particular religious doctrine as unacceptable, but she still may find reasons to tolerate its existence. Call this the paradox of an initial acceptance.

The second major aporia of tolerance is that determining its limit proves to be a difficult task after the opposed doctrine in question has already been deemed worthy of acceptance. To use the previous example, the initially tolerated religious doctrine cannot be tolerated to the extent that it infringes the rights of the tolerating party. This is known as the paradox of "tolerating the intolerant", and it poses a problem even for the most liberal approaches. As Karl Popper (2013, p. 581) argued, "Unlimited tolerance must lead to the disappearance of tolerance". Call this the paradox of a secondary acceptance since it arises after a tolerant attitude is already adopted towards something that has been found permissible. ${ }^{1}$

1 John Horton's (1994) and Rainer Forst's (2013, pp. 19-26) classifications include the third paradox, in addition to the two discussed in this article. According to Horton (1994, pp. 16-18), the third paradox describes a counterintuitive situation, where it may turn out that a person who has more negative attitudes is more tolerant than the one that is more receptive to other worldviews. Forst (2013, p. 19) discusses this paradox in connection with the first component of tolerance that he outlines - the "objection component". He illustrates the problem by alluding to the paradox of a "tolerant racist". To address this problem I will simply accept Horton's (1994) solution that tolerance denotes not only an action, but it is, first and foremost, an attitude. For this reason, racist attitudes are excluded from the very start. 
A convincing liberal theory is required to accomplish two divergent tasks: first, in addressing the first paradox, it should determine how substantive ethical worldviews can be overridden by a tolerating attitude; and second, it should pose at the same time the limit of tolerance taking into account the fact that comprehensive doctrines can no longer be endorsed to accomplish this task. The prevailing solution to this paradoxical situation has been a reworking of the Kantian deontological liberalism with its emphasis on universal morality in the service of the ethically neutral state. Morality in neo-Kantian theories is understood as a special subset of ethics and is recognized as the cornerstone of human agency. Jürgen Habermas and Rainer Forst are the major proponents of this view, according to which higher-order moral reasoning in the form of deontic precepts of reciprocity and generality helps us to evade the impasse by defining universally acceptable criteria of tolerance.

As I argue in this paper, the proposal of an ethically neutral conception of tolerance is unpersuasive. The principles of reciprocity and generality necessarily require grounding in particular ethical norms (such as freedom and equality). And once they are grounded in such norms, it is difficult to explain in what sense they are universal in a Kantian sense (and not arbitrary). In view of this, deontological liberalism does not manage to provide universal standards of tolerance that can be applied across various contexts.

I argue that against the backdrop of the failure of deontological liberal approach, a Derrida-influenced view can solve the conundrum not by suspending the paradoxes of tolerance but by acknowledging their permanence. Jacques Derrida (2005c, p. 150) argues that justice needs a necessary grounding in the existing ethical worldviews and empirical realities in order to operate. However, he shows that despite (or rather, thanks to) such grounding in particular norms or empirical realities, it becomes necessary to go beyond the established status quo (Derrida, 1992a, pp. 22-25).

In the following, I will first show how the conceptualization of tolerance within the framework of deontological liberalism leads to a dead end. Then, I will argue that an aporetic approach to tolerance inspired by Derrida can be the way to sidestep the impasse. 


\section{Tolerance as a moral principle within the neo-Kantian deontological Framework}

The central claim of deontological liberalism is that a higher-order form of reasoning - morality takes precedence over particularist ethical doctrines or political expediency. Deontological liberals contend that otherwise, comprehensive doctrines can easily encroach upon the freedoms of those citizens who hold a variety of ethical beliefs. Of central importance is the construction of the domain of morality that is supposed to be legitimate in the eyes of the adherents of various ethical doctrines. This is achieved by making morality devoid of any connection with particularist ethical worldviews.

On this view, the priority of universal morality over particularistic ethical doctrines must not be part of any type of modus vivendi, but rather it should raise independent validity claims. In other words, moral values advocated by a deontological approach have to be right or wrong in a similar sense as truth claims are either true or false. Based on this argument, Jürgen Habermas (1998, p. 85) objects to John Rawls's concessions to modus vivendi by arguing against depriving such a cognitive status to the claims of morality. Habermas contends that Rawls "must allow some epistemic relation between the validity of his theory and the prospect of its neutrality toward competing worldviews being confirmed in public discourses" (Habermas, 1998, p. 63). What unites Habermas with another principal liberal theorist, Rainer Forst is that for them no concession to practical expediency or ethical worldviews is permissible if it violates the priority of morality over particularistic ethical doctrines. Moral justification is supposed to be the ultimate arbiter of ethical validity claims, superseding all sorts of comprehensive doctrines (Forst, 2012, pp. 93-96; Habermas, 1998, p. 62).

Regardless of such a strong epistemic status attributed to the claims of morality, the priority of morality over particularistic ethical doctrines does not result in a reinstatement of metaphysics. Instead, deontological liberalism maintains that morality, in a Kantian sense, is the only adjudicating mechanism that is capable of bridging the gap between ethical doctrines and universal human reasoning and can provide means for a successful political cooperation.

For deontological liberals, tolerance is a moral principle, rather than a part of some particularist comprehensive doctrine. The gist of this 
argument is the following: ethical attitudes or inclinations either completely renounce tolerance or admit of differing opinions or dispositions on arbitrary grounds. According to the deontological view, even if a state or a person practices tolerance towards the followers of non-official comprehensive doctrines out of benevolence, this would not be normatively justified. The reason for this is that the tolerating party will only extend tolerance as grace without justifying it on normative grounds. (In a similar vein, Goethe's famous saying "tolerance is offensive" is predicated on the model of a strictly subject-centred, non-universalizable conception of tolerance). To avoid condescending benevolence, it is argued that we need to go beyond comprehensive doctrines or private interests and transpose the problem on a higher-order, moral level. At this level, one can deliver universally valid and objective judgements that are neutral with respect to all comprehensive doctrines (Forst, 2013, pp. 23-36; Habermas, 2008, p. 258).

Forst lists two main deontic precepts that should guide our judgement of tolerance. The first is the rule of reciprocity which means that "nobody can make certain claims (to the validity of norms, to rights or resources) which he denies to others (reciprocity of contents), and that one may not simply assume that others share one's perspective, one's values, convictions, interests or needs (reciprocity of reasons) by claiming to speak in their 'real' interests (and arguing accordingly that, 'reciprocally' speaking, one would be glad to be treated or coerced as they are)" (Forst, 2013, p. 454). The principle of reciprocity would guarantee universality as it supposes that actors consider not only their private interests or values, but what is justified from a perspective of an average rational individual. This is considered to be a universal standpoint and results in an equal benefit to all. An actor is expected to imagine what could be universally valid from the perspective of a second person; Habermas (1998, p. 42) calls this a mutual "perspective-taking”. Reciprocity is accepted as a major stepping-stone for building a universally justified moral theory of tolerance. It requires every citizen not to appeal to a higher truth that is not accessible to others (Forst, 2013, pp. 454-455).

The second deontic precept of generality is defined as a requirement to take into account the claims of every single individual, instead of brokering an agreement between the selected parties. Forst (2013, p. 455) argues that each person has a "moral veto right," that is, everyone can reject the 
definitions of tolerance that she or he finds unacceptable. Generality guarantees the broadest scope of a mutual perspective taking.

Now, juxtaposing the two different levels of argumentation or the "contexts of justice" (Forst, 2002) aims to solve the first paradox of tolerance by introducing the principle of the priority of morality over particularistic ethical doctrines into the domain of politics (Forst, 2013, pp. 459-460; Habermas, 1996, pp. 459-460). Initially, one accepts the rejected doctrine not because it is justified from a subjectivist point of view - i.e., solely, from the standpoint of some ethical doctrine, but because it is neutral towards every such worldview. ${ }^{2}$ Universal morality, with its deontic precepts of reciprocity and generality, must dictate what to tolerate, and comprehensive doctrines are expected to fine-tune their principles to it (Habermas, 2008, pp. 81-84; Forst, 2012, pp. 93-96). One should tolerate different political, religious or other sorts of worldviews because from the perspective of reciprocity and generality - i.e., a perspective that is neutral towards particularist doctrines, every view ought to enjoy equal moral status. Ethical worldviews, in contrast, cannot stand the test of reciprocity and generality, since they are only espoused on particularistic grounds, that is, without taking into considerations the claims of the individuals adhering to different comprehensive doctrines.

The second paradox of tolerance is solved in the same manner. The neoKantian conception of morality, with its deontic precepts of reciprocity and generality, provides a mechanism to regard certain doctrines as intolerable. However, as this is done in the name of universal morality, the exclusion is viewed as morally justified and not as arbitrary. In other words, one must believe that ethical doctrines do not have a say in designating certain worldviews as intolerable, and the act of exclusion is solely based on higher-order moral reasoning. For example, Habermas (1998, pp. 225-226) argues that the exclusion of fundamentalist worldviews stems from the neutral stance of rational actors vis-à-vis comprehensive doctrines, as opposed to being based on an arbitrary decision. Likewise, Forst (2013, p. 563) discusses positions that involve "the refusal to relativize one's claims to religious truth either in the moral or in the epistemic sense as required by the use of practical and theoretical reason". He characterizes such positions as "fundamentalist"

${ }^{2}$ According to Forst (2013, pp. 524-535), such an acceptance implies showing respect towards tolerated doctrines by acknowledging their distinctiveness. For the other prominent example of this "respect conception of tolerance", see Galeotti (2004). 
and argues that it is not a fundamentalism per se to reject such views. For Forst (2013, p. 564), tolerance does not impose any particularist doctrine for example, a pluralistic, or an atheistic interpretation of the world - but instead, it simply calls for mutual respect.

\section{Is It Possible to Overcome the Particularistic Nature of Tolerance?}

I argue that the main problem with the deontological liberal approach to tolerance is that the purported universality of the precepts of reciprocity and generality is dubious. Let us first look at the deontic precept of reciprocity. According to Forst (2013, p. 454) reciprocity implies that no group can claim something that it denies to others. In more formal terms, this principle requires that if an agent $\mathrm{A}$ claims something $\mathrm{P}$ in the circumstances $\mathrm{X}$ (for example, making their religious views prevalent in a given society), then any agent $\mathrm{N}$ cannot be denied to the same claim $\mathrm{P}$ in the same circumstances $\mathrm{X}$. The problem with this argumentation is that it is either too general and does not affirm the value of tolerance (1) or it requires grounding in concrete norms drawn from particular ethical doctrines (2). Let us look closer at both objections.

(1) If reciprocity follows this very general schema, then the result is not necessarily a tolerant attitude. This model does not tell us why we should tolerate others who do not adhere to our values. To illustrate why this is so, we can imagine the world full of religious doctrines oriented on a full political domination. Under this scenario, accepting the general definition of tolerance may even lead to "the war of all against all". For, agent A may acknowledge that agent $\mathrm{B}$ has a right to dominate others, without establishing permissible boundaries of a potential conflict. Anyone may acknowledge the enemy's right to wage war against her, without setting any limit to what such confrontation entails.

(2) Grounding tolerance in concrete norms such as freedom and equality solves the above-mentioned problem. It can be now argued that agent A can lay claim to the rights based on equality and freedom in the circumstances X, if such a claim does not violate any other agent N's rights. But such a solution comes at a price. Even such supposedly universal values as freedom and equality are still "parochial", in the sense of being part of particular comprehensive doctrines. Both of these values can be interpreted very differently. For 
example, equality can be interpreted very formally, as guarantying minimal negative freedoms for all individuals. Or it can entail something as demanding as libertarian socialism. Moreover, both of these values are still shaped by the particular political, cultural or even, empirical circumstances. For example, one may also argue that we should tolerate the infringement of our equal freedoms for a greater good: be it winning a just war, or defeating a global pandemic. In such extreme scenarios, tolerance for "others" might be temporarily trumped in the name of such necessities as maintaining order or halting the spread of a virus. The list of such exceptions that may trump the considerations of the current understanding of equality and freedom are potentially innumerable. For this reason, tolerating something seems to be contingent upon the acceptance of particular comprehensive worldviews or empirical constraints, rather than being universally justified, in a Kantian, moral sense. As Lasse Thomassen (2008, p. 87) aptly summarizes in his thorough critique of Habermas, "tolerance is necessarily inventive; it must invent its own law because there can be no law, no regulative idea or critical ideal, expressing what tolerance is and which we can follow".

The principle of generality faces the same kind of problem when applied to the real world. It presumes that all individuals should partake in determining the contours of tolerance. However, it is far from clear what independent, universal criteria we have to determine who counts as an individual entitled to full political and civil rights. Not only is the definition of an "adult" and a "citizen" contestable, but also, the question of who counts as a "normal human" has also been subject to controversy. For example, racial minorities or LGBTQ people have been long considered less than human in the West. Some LGBTQ people still do not enjoy equal formal human rights in some European countries. Recently, the issue of transgender rights has become the subject of the same kind of controversy as LGBTQ rights were in the past. There is no guarantee that in the future, what constitutes a "human" will not be up for debate. Thus, the deontic precept of generality is also arbitrary and dependent upon comprehensive worldviews that we endorse.

Recall that in the beginning, I argued that a convincing liberal theory is required to accomplish two divergent tasks: first, in addressing the first paradox, it should determine how substantive ethical worldviews can be overridden by a tolerating attitude; and second, it should pose at the same time the limit of tolerance taking into account the fact that comprehensive doctrines can no longer be endorsed to accomplish this task. Based on the foregoing, 
it seems that deontological liberalism fails to accomplish both of these two tasks. The first paradox of tolerance remains in place, because deontological liberalism cannot explain how a person can tolerate something that she strongly objects. Once it is apparent that grounding tolerance in particular values is unavoidable, it becomes difficult to explain how one can tolerate someone who is not covered by her definition of tolerance, without succumbing to a paradox. In a similar manner, the second paradox of tolerance cannot be superseded by the deontological liberalism. Once it is clear that setting limit to tolerance is always dictated by the endorsement of particular values (such as freedom and equality) or the definitions of what constitutes a "human", tolerating the intolerant remains something that is arbitrary.

Below, I will show that Derrida's deconstrutive approach to justice can avoid the deadlock at which deontological liberalism arrives. Deconstruction does not need to ignore the necessity of grounding tolerance in particular ethical worldviews or empirical contexts. However, despite accepting the necessary particularity of tolerance, Derrida's approach can still account for its context-transcending, "universalistic" potential. Below, I will explicate how this can be done.

\section{Maintaining tolerance as a paradox in Derrida's deconstruction}

There are two general characteristics of the Derridean approach: first, it regards normative acts as having a supererogatory nature. In other words, on this view, such acts go beyond pre-established duties. Such duties stem not only from comprehensive doctrines and deontic precepts but also from economic calculations and legal norms (Derrida, 1992a, pp. 24-25). Second, Derrida believes that this supererogatory nature of justice stems from it being intrinsically bound up with the very forces of the status quo that it seeks to transcend. In this way, it is different from the traditional accounts of supererogation, which generally consider supererogatory acts as being purely gratuitous.

Below, I will make a quick detour and first outline the defining characteristics of the Derridean justice and, second, I will show how tolerance can be imagined within such a framework. 


\section{The paradoxical nature of justice}

In order to grasp the paradoxical nature of the Derridean deconstruction, we need to delineate it from the prevailing conceptions of supererogation. The classic accounts of supererogation, such as Urmson's (1958), or Chisholm's (1982, pp. 98-113), are generally concerned with the classification of normative acts without elaborating much on the nature of normativity, in general (which they largely take for granted). In contrast, Derrida (1992a, p. 27) argues that purely normative (including, supererogatory) decisions do not exist as every act is necessarily tainted by different sorts of rules and calculations and is subject to different interpretations. Moreover, acting in conformity with some comprehensive doctrine is akin to the application of a pre-existing rule-sometimes for the private benefit. The same holds true for duties that are prescribed by deontological liberal approaches, such as Habermas's and Forst's. In short, according to the Derridean approach, there must be something more to justice that predetermined normative doctrines cannot capture.

If justice is not something that exists independently of pre-existing normative or legal doctrines, but at the same time, it cannot be determined fully by them, how can we conceive it at all? Is it merely an illusion - a vain ideal, or does it have a grounding in reality? Derrida believes in the latter and claims that such paradoxes or aporias are integral elements of our reality.

In order to understand better why a necessary determinateness or ruleboundedness of a normative act implies the call for a transcendent other and vice versa, we need to examine Derrida's late works and the "idea" of undecidability. Derrida starts from asserting that every decision undergoes an ordeal of the undecidable as otherwise, the decision would not be just but merely an application of a rule - i.e., be a product of a determinate context (Derrida 1992a, pp. 22-25). For example, if it were possible to completely forego the supererogatory nature of ethics and adhere steadfastly to certain rules or calculations, then we would not be able to deliver a "fresh judgement" (Derrida uses precisely this English expression - 1992a, p. 23). So long as every new context poses at least a conceptual challenge to the existing norms, we need to transcend the boundaries of the pre-established doctrines and acquire a new understanding of the out-of-the-box situations. To take the already mentioned example, even such supposedly universal value as human rights is not immutable, since what constitutes a proper "human" is 
sometimes called into question. Moreover, normative acts are not just based on calculations, but they necessarily transcend what is in the actors' interests or even reciprocal agreements. If this were not the case, then it would be impossible to achieve justice as the latter involves an act that is not merely practical from the economic point of view but also just from a hypothetically context-transcending standpoint.

At the same time, from a Derridean perspective, justice cannot be detached completely from the preconceived set of norms, or economic calculations. It is hard to imagine a principle that has cut all links with the pre-existing notions of justice and is not at least partially traceable to already established norms. Similarly, almost every normative act involves an element of economic transaction. One is never entirely sure whether an act is gratuitous as there is always a chance that what at first glance seemed a pure instance of gratuity, was in fact driven by egotistic calculations. "Whether it is a question of singularity or universality, and each time both at once, both calculation and the incalculable are necessary", argues Derrida (2005c, p. 150). ${ }^{3}$ Even in such seemingly purely altruistic instances such as an anonymous blood donation, it is hard to prove that no psychological benefit was accrued to a benefactor. The egotistic element cannot be ruled out as long as one can be expected to receive a certain material (in the case of familial altruism) or psychological (in the case of anonymous blood donations) benefits in her lifetime.

Recast in such terms, it turns out that justice has an aporetic structure; it is an enabling condition, rather than a negative ideal, that can never be achieved and for this reason, may drive human beings to nihilism. Democracy will never exist, "not because it will be deferred, but because it will always remain aporetic in its structure" [emphasis added] (Derrida 2005c, p. 86). Elsewhere, Derrida's (1982, p. 5) claims that différance is "what makes possible the presentation of the being-present, it is never presented as such". The same logic applies to justice, which is a cognate of différance (the latter is named by Derrida at various points as trace, iterability, archewriting, khôra, democracy-to-come, etc.). If it were even possible to catch the very moment when justice is achieved, it would be impossible to maintain

3 On Derrida's deconstructive approach to justice and the relationship between calculable and incalculable see Cornell et al. (1992), Beardsworth (1996), Cheah and Guerlac (2009), Haddad (2013). 
it. As it was already argued above, any just decision quickly establishes itself as part of a rule, a convention or a doctrine, as the very moment justice comes into force quickly evaporates and gives ground to the forces of conditionality. Even sacrificing one's own life cannot be perceived as "just" in an absolute sense as the reasons behind individual actions are not absolutely transparent. (This is especially true of the deeds undertaken by religious saints - a favorite example of the mainstream theorists of supererogation.)

To summarize, (a) every normative act is necessarily bound by determinate rules or calculations, but (b) it has a capacity to transcend its defining limits. As we have seen, Derrida does not regard this as a problem as he openly endorses an aporetic nature of justice. Below, I will show how the paradoxes of tolerance can be accounted for with the help of the Derridean deconstructive approach to justice.

\section{Accounting for the paradoxes of tolerance}

To better explicate how the aporetic structure of justice relates to the question of tolerance, we may look at Derrida's treatment of the subject of hospitality. According to him, a host is necessarily a sovereign in his own realm. Otherwise, he or she loses the right to welcome and receive a guest. "Anyone who encroaches on my 'at home', on my ipseity, on my power of hospitality, on my sovereignty as host, I start to regard as an undesirable foreigner", writes Derrida (2000, pp. 54-55). Moreover, it is not only that being a host requires sovereignty rights over one's own abode, but also, hospitality is necessarily limited by certain limiting condition. For example, not all guests are received indiscriminately; especially, those that would encroach on one's "at home", are not welcome. The host decides whom to offer a shelter and whom to reject (Derrida, 2000, pp. 54-55). ${ }^{4}$

We can argue that a similar logic applies to the question of tolerance as well, since the latter also necessarily imposes its own limits on a tolerating side despite the fact that it is simultaneously a context-transcendent attitude. In this sense, paradoxes are inherent to the practice of hospitality as much as they are inherent to tolerance. In both cases, conditionality and

${ }^{4}$ Derrida (1992b) develops a similar deconstructive reading of a gift. For a contrary view, see Heyd (2005) and Ungureanu (2013). 
unconditionality are each other's enabling conditions (Derrida, 2000, p. 147; 2005a, pp. 44-45). ${ }^{5}$ By “conditionality”, following Derrida, I mean that way how tolerance is bound up with certain comprehensive doctrines or particular empirical realities. "Unconditionality", in contrast, refers to the way how tolerance, despite its particular, context-bound character, is still a radical force that reaches out to cover those who are not expected to be tolerated by the dominant normative worldviews (or are not expected to be tolerated due to pragmatic or even existential reasons).

From the Derridean perspective, the first paradox of tolerance can be accounted for by arguing that justice requires paradoxes in order to exist as justice. Otherwise, one is trapped within the confines of particularist doctrine that only prescribes something that is already part of the dominant comprehensive worldview. Tolerating something that is not part of your worldview is a basic requirement to be just. Justice, as Derrida (1992a, p. 23) argues, needs a "fresh judgement" that arises only in case one is ready to forego some of the previously held beliefs. This does not of course amount to erecting a layer of universal morality - including such purportedly universal mechanism as reciprocity or generality - on top of the privately held ethical beliefs. Doing so would again annul justice, as the latter necessarily requires going beyond not only any particularistic doctrine but also any type of a predetermined rule or a program.

The second paradox of tolerance, likewise, is accounted for by drawing on the paradoxical nature of justice. As I have shown, from the Derridean perspective, universality cannot be attained in an absolute sense, as it would amount to the reinstatement of the sacredness of certain moral acts. For this reason, tolerance is necessarily bound by certain conditions and rules that make it impossible for anyone to be absolutely tolerant; every time such a claim arises, it is immediately checked by certain "conditionality".

To summarize, by taking cues from Derrida's deconstruction, I argue that we need to simultaneously set a limit to tolerance and leave the space open for transcending such a limit. In this way, the paradoxes of tolerance

5 In Faith and Knowledge, Derrida (2002, p. 59) Derrida distinguishes between the two senses of tolerance. On the one hand, tolerance is a Christian ideal; it is deeply rooted in the concrete religious tradition that heavily influenced the Western Enlightenment. On the other hand, Derrida believes $(2002$, p. 60) that there could be another type of tolerance that would "respect the distance of infinite alterity as singularity." This latter understanding of tolerance is what I try to unravel in this article. 
can be maintained, instead of superseded. After looking at this argument, one may ask the following question: if the paradoxes of justice and hence, tolerance, cannot be superseded, then what is their nature? Several commentators already have alluded to such a nature of deconstruction. ${ }^{6}$ In his late works, Derrida (2005b, p. 91) himself acknowledges the quasi-transcendental character of his critical expositions. Quasi-transcendentalism here alludes to the revised architectonics of the Kantian transcendental idealism. Unlike Kant, Derrida does not seek to establish the conditions of experience that are extra-temporal and ahistorical. The paradoxes of tolerance are heavily grounded in a concrete reality and the element of particularity cannot be predicted preliminarily. There is no categorical, clear-cut rule, like reciprocity or generality that would dictate how tolerance should be exercised. Despite this, the quasi-transcendental paradoxes are crucial for understanding the way tolerance works and why it should be nurtured.

\section{Conclusion}

In the beginning, I outlined two major paradoxes that characterize tolerance in contemporary liberal theory. The first problem concerns the difficulty of tolerating the views that challenge one's deeply held beliefs. The second paradox asks where the threshold of such toleration lies. As I have shown in this article, neo-Kantian deontological view fails to accomplish the task that it sets before itself - namely, to supersede the paradoxes of tolerance. Neither Habermas nor Forst can ignore the fact that ethical doctrines necessarily affect a tolerating act in such a way that tolerance is never universal but instead, dependent upon prior particularist norms or empirical circumstances. For this reason, deontological liberalism cannot provide a completely non-arbitrary standard of tolerance which will help to overcome the paradoxes outlined in this article.

The Derridean aporetic conception of tolerance, in contrast, does not seek to overcome the paradoxes. Instead, it admits that tolerance is necessarily grounded in particular comprehensive doctrines or empirical realities. But despite its necessarily particularistic character, tolerance

${ }^{6}$ See Gasché (1986), Bennington (1993, 2000), Rorty (1995b), Fritsch (2011), and Doyon (2014). 
never loses its emancipatory, context-transcending potential. According to this view, it is imperative to maintain the tension between the two different facets of tolerance - the one tied to a determinate context, or rules, and the other that always tries to transcend its own finite context. In this way, it will be possible to entertain the possibility of a self-negating tolerant act without losing ground to a neo-Kantian universal morality deracinated from any determinate context. And as I argued above, since paradoxes cannot be thrown away, they can be construed as having a quasi-transcendental nature.

\section{References}

Beardsworth, R. (1996). Derrida \& the Political. London-New York: Routledge.

Bennington, G. (1993). Jacques Derrida. Chicago-London: The University of Chicago Press.

Bennington, G. (2000). Interrupting Derrida. London-New York: Routledge.

Cheah, P., Guerlac, S. (eds.) (2009). Derrida and the Time of the Political. DurhamLondon: Duke University Press.

Chisholm, R. (1982). Brentano and Meinong Studies. Atlantic Highlands, N.J.: Humanities Press.

Derrida, J. (1982). Margins of Philosophy. Brighton: The Harvester Press.

Derrida, J. (1992a). Deconstruction and the Possibility of Justice. New York: Routledge.

Derrida, J. (1992b). Given Time I. Counterfeit Money. Chicago: The University of Chicago Press.

Derrida, J. (1994). Specters of Marx: The State of the Debt, the Work of Mourning and the New International. New York: Routledge.

Derrida, J. (2000). Of Hospitality: Anne Dufourmantelle Invites Jacques Derrida to Respond. Stanford: Stanford University Press.

Derrida, J. (2002). Acts of Religion. New York and London: Routledge.

Derrida, J. (2005a). On Cosmopolitanism and Forgiveness. London-New York: Routledge.

Derrida, J. (2005b). Paper Machine. Stanford: Stanford University Press.

Derrida, J. (2005c). Rogues: Two Essays on Reason. Stanford: Stanford University Press. 
Doyon, M. (2014). The Transcendental Claim of Deconstruction. In: D. Zeynep, L. Lawlor (eds.), A Companion to Derrida (pp. 132-150). Oxford: Willey Blackwell.

Forst, R. (2002). Contexts of Justice: Political Philosophy beyond Liberalism and Communitarianism. Berkeley: University of California Press.

Forst, R. (2012). The Right to Justification. New York: Columbia University Press.

Forst, R. (2013). Toleration in Conflict: Past and Present. Cambridge: Cambridge University Press.

Fritsch, M. (2011). Deconstructive Aporias: Quasi-Transcendental and Normative. Continental Philosophy Review, 44, 439-468.

Galeotti, A.E. (2004). Toleration as Recognition. Cambridge: Cambridge University Press.

Gasché, R. (1986). The Tain of the Mirror: Derrida and the Philosophy of Reflection. Cambridge, MA-London: Harvard University Press.

Horton, J. (1994). Three (Apparent) Paradoxes of Toleration. Synthesis Philosophica, 9 (1), 7-20.

Habermas, J. (1996). Between Facts and Norms: Contributions to a Discourse Theory of Law and Democracy. Cambridge, MA: The MIT Press.

Habermas, J. (1998). The Inclusion of the Other: Studies in Political Theory. Cambridge, MA: The MIT Press.

Habermas, J. (2003). The Future of Human Nature. Cambridge: Polity Press.

Habermas, J. (2008). Between Naturalism and Religion. Cambridge: Polity Press.

Haddad, S. (2013). Derrida and the Inheritance of Democracy. Bloomington-Indianapolis: Indiana University Press.

Heyd, D. (1996). Toleration: An Elusive Virtue. Princeton: Princeton University Press.

Heyd, D. (2005). Supererogatory Giving: Can Derrida's Circle be Broken? Jahrbuch für Recht und Ethik / Annual Review of Law and Ethics, 13, 149-165.

King, P. (1998). Toleration. New Edition. London: Frank Cass.

Müller, F.S. (2013). Justifying the Right to Justification: An Analysis of Rainer Forst's Constructivist Theory of Justice. Philosophy and Social Criticism, 39 (10), 1049-1068. 
Popper, K. (2013). The Open Society and Its Enemies. New One-Volume Edition. Princeton-Oxford: Princeton University Press.

Thomassen, L. (2008). Deconstructing Habermas. New York: Routledge.

Ungureanu, C. (2013). Bourdieu and Derrida on Gift: Beyond 'Double Truth' and Paradox. Human Studies, 36 (3), 393-409.

Urmson, J.O. (1958). Saints and Heroes. In: A. Melden (ed.), Essays in Moral Philosophy (pp. 198-216). Seattle: University of Washington Press.

\section{THE PARADOXES OF TOLERANCE: A DECONSTRUCTIVE VIEW}

\section{Summary}

The neo-Kantian, deontological liberal theory seeks to overcome the paradoxes of tolerance. It claims to accomplish this task by grounding tolerance in purportedly universal higher-order moral reasoning. I argue that in reality, such an approach cannot separate tolerance from particular ethical norms or empirical realities. For this reason, it cannot resolve the paradoxes of tolerance. However, I contend there is another path to account for the value of tolerating "others". Jacques Derrida's deconstruction provides us the way to retain the necessarily particularistic character of tolerance, without forfeiting its context-transcending, "universalistic" potential. In this article, I show that the paradoxes of tolerance need to be maintained as quasi-transcendental structures, instead of being discarded in the name of higher-order moral reasoning. 